the rays of sunlight pass directly through these apertures and are received on the sensitised surface of a photographic paper or chart placed inside. By reason of the earth's rotation, the spot of sunlight thus obtained travels over the chart in a more or less curved line (according to the season), marking its path by a clearly-defined blue trace, which can be rendered permanent by simply im- mersing the paper for a few minutes in cold water. The position of the sun in relation to the instrument at the different hours of the day will be understood by reference to the figure, which is a cross-section through the cylinder; the dotted circle shows the position of the prepared chart, The screen, $c d$, is for the purpose of cutting off the rays from the eastern aperture at noon, and at the same time

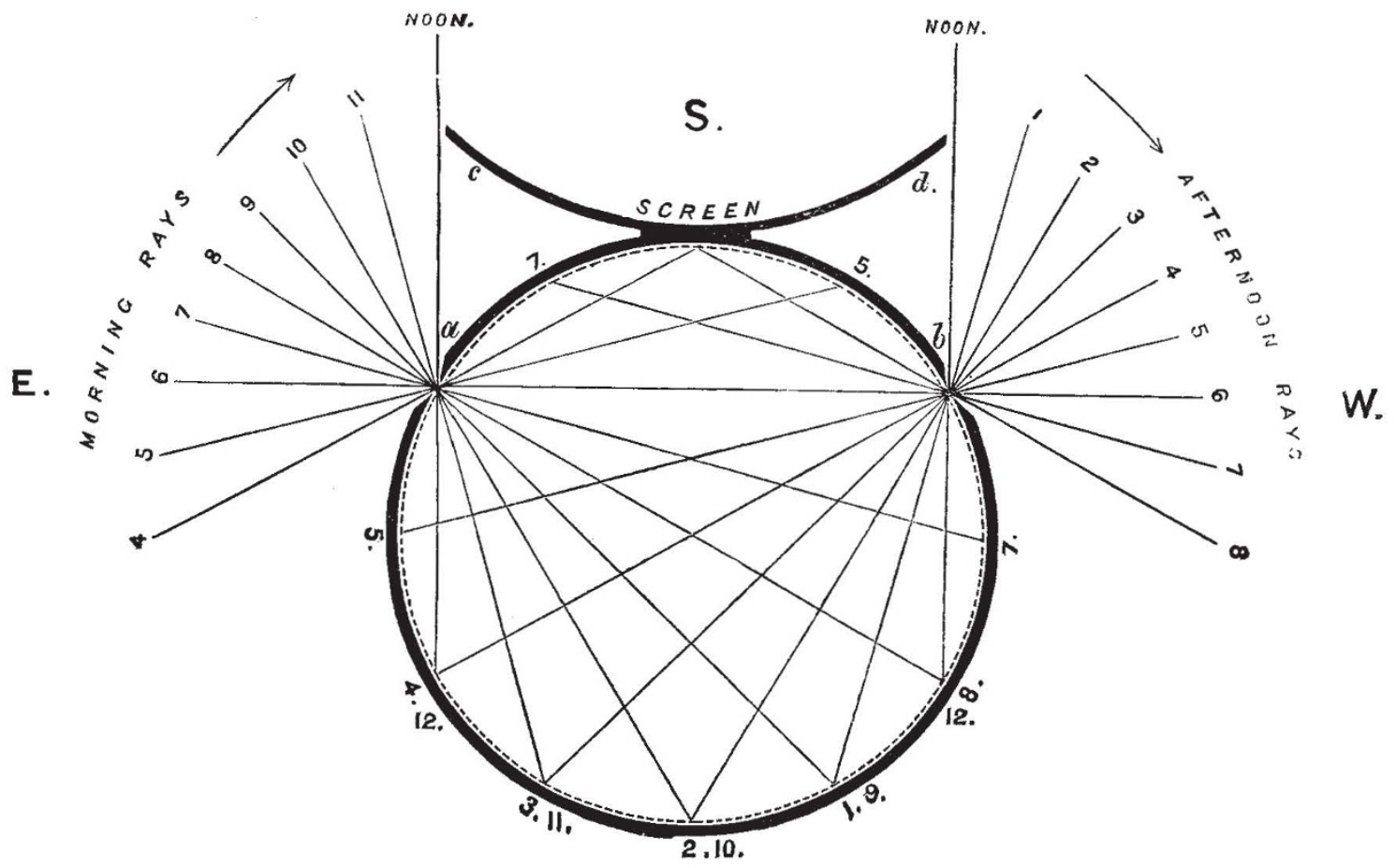

allowing them to pass through the western aperture ; it results, but when the sun is partially obscured by haze or also forms a protection from rain and diffused light.

Observations made with this instrument prove that photography is well adapted for recording the duration of sunshine, and under some conditions it has advantages over the burning method. At those times when the atmosphere is perfectly clear the two methods give similar thin cirrus cloud there is a difference in the records obtained. The result of a month's comparative observations, taken in June last, gave an excess of I I per cent. of sunshine recorded by the photographic process, this variation being mainly due to a hazy atmosphere near the horizon about the times of sunrise and sunset.

\section{METEOROLOGY IN THE NEW ENGLAND STATES ${ }^{1}$}

$T$ HE New England Meteorological Society was founded in June, 1884 , with a membership of 9 , which at the close of its first year had risen to 95 . Notwithstanding this very modest commencement, it has succeeded, largely through the generous co-operation of friends who have from time to time contributed liberally to its resources, in keeping its expenses within its income, while at the same time it has regularly published its Monthly Bulletin of eight pages, including a weather-map for the month; largely added to its observing stations; and largely extended the sphere of its operations. The annual fee for membership, which constitutes the whole income of the Society, is three dollars.

During its first year, ending last October, the Society has addressed itself more particularly to the securing of a corps of reliable observers of meteorological phenomena, with special attention to rainfall and temperature ; the publication of the Monthly Bulletin; the dissemination of the daily indications of the U.S. Signal Service; the local display of weather-flags; and the special

${ }^{2}$ Bulletin of the New England Meteorological Society, Nos. i. to xii. Nov. 1884 , to Oct. 1885 ). investigation of thunderstorms. The first number of the Bulletin contained reports from forty-five observers; but, so vigorously was this important branch of the Society worked out, that in September the number had risen to 123 observers. The greatest attention has been given to secure uniformity in the instruments and methods of observation. In the last-published Bulletin the amount of precipitation and the mean temperature are given in Table I. for thirty-five places, these being at the same time compared with the averages of previous years, which range from eleven to seventy-four years. Table II. gives a succinct summary of the results of the observations of temperature, pressure, humidity, and precipitation at the I23 stations, and the weather-map shows graphically the precipitation and range of temperature for the month.

A striking feature of the Society's work is its hearty co-operation with the U.S. Signal Service in the dissemination of daily forecasts of the weather, and the local display of weather-flags. A member of the Signal Corps has been assigned to this duty under the Society's control, with the gratifying result that local weather flags are daily displayed in upwards of roo cities and towns of New England.

The special investigation of thunderstorms has been conducted under the supervision of the Secretary, Mr. Well 
Davis, of Harrard College. The National Academy, which constitutes the trustees of the Bache fund, has granted 200 dollars for this work. Upwards of 400 observers are co-operating in the inquiry, and as regards one thunderstorm reports from 203 observers were received. The discussion of the important results already obtained will by and by appear in the Bulletin. A thorough investigation of thunderstorms, including the falls of rain, snow, and hail, with their successive propagation over the New England States, will be a highly important contribution to meteorology; and for the results of the investigation as it advances we shall look with much interest to the proceedings of this Society, which is among the very youngest but most active of the meteorological societies.

\section{NOTES}

WE much regret to record the death of Sir Frederick J. O. Evans, R.N., K.C.B., F.R.S., late Hydrographer of the Admiralty, in his seventy-first year. Next week we hope to give a notice of Sir Frederick's career.

His Excellency the Minister of Agriculture, Industry, and Commerce in Italy, in order to favour and facilitate the application of remedics in solution, powder, or mixture against the cryptogams and parasites of cultivated plants, and especially the use of milk calx against Peronospora (mildew) of the vines, by a decree of November 9 will open an International Exhibition with prizes for pumps, watering and pulverisation implements. The Exhibition will take place at Conegliano in the Royal School of Vine-Culture and Enology. The following prizes will be awarded :-I gold medal and 500 lire ; 3 silver medals with 150 lire each; 5 bronze medals. The Ministry of Agriculture will also purchase prize implements to the value of I000 Iire for distributing to the Agrarian Government depots, practical and special agriculture schools. Exhibitors must apply for admission to the "Direzione della R. Scuola di Viticoltura ed Enologia in Conegliano" not later than February 22, 1886. The demand must contain a short description of the instruments and the price of each object to be exhibited.

Ir is stated that the Mexican Government are about to establish a meteorological station among the highest mountains in Mexico, at an elevation of nearly 20,000 feet above the sealevel. Access to such a place must be always precarious, and frequently impossible for a long time together, hence it is necessary to make exceptional provision for rendering the instruments almost independent of human attention and supervision. The necessary apparatus is being constructed by Hottinger, of Zurich, and, as far as possible, all the instruments are being made to go for a year without stopping.

AT the monthly meeting of the Council of the Sanitary Assur. ance Assaciation arrangements were completed for the series of free lectures to be given by the Association at the Parkes Museum during January and February next. The first lecture is to be by Prof. Roger Smith, on "A Damp House," on Wednesday evening, January 20 , and on the following Wednesday Mr. F. B. Jessett, F.R.C.S.Eng., will lecture on "Preventible Diseases."

THE science certificates and prizes obtained by the students attending evening classes established by the Birmingham SchoolBoard were distributed by Prof. Lapworth, LL.D., F.G.S., in the large hall of the Icknield Street School, on December 14. The report of the year's work, by the Board's demonstrator, Mr. W. J. Harrison, F.G.S., showed that some 5000 children are now receiving elementary instruction in science in the day. schools, while 500 teachers attend the evening classes. Prof. Lapworth afterwards delivered a very able and scholarly address.
In consequence of the rapid growth of the system of science teaching, the Board has just resolved to enlarge the chemieal laboratory at a cost of about $700 l$.

THE Clothworkers' Company have promised to raise their annual subscription to the City and Grilds of London Institute from 3000 l. to $4000 \%$., provided the Corporation and Associated Livery Companies raise the total of their annual subscriptions to the Institute from $24,500 l$, the present amount, to $30,500 l$. This is probably the first step in response to Lord Selborne's recent appeal to the City Companies, on the double ground of public duty and self-interest, to add still further to their already munificent contributions to technical education. The capital expendi. ture on the building and equipment of the Central Institution, Exhibition Road, the Finsbury Technical College, and the South London School of Technical Art has been nearly $140,000 \%$, but, as the late Lord Chancellor pointed out, the Companies cannot be said to have discharged their obligations to technical education, until the Institute wants no more pecuniary support and moral countenance. Until this distant goal is reached, said Lord Selborne, they remain in its debt, notwithstanding their already vast donations.

THE statement, according to Science, that one of the chief applications of composite photography will be in the direction of producing more reliable portraits of representative men by com. bining the testimonials of individual axtists, will probably be accepted by all who have followed the short but interesting career of this new invention. The suggestion that, by combining the individual conceptions of several artists, one would obtain a more reliable portrait than any of the components, was near at hand. The first such application was made by $\mathrm{Mr}$. Galton himself. He made a composite of six medallion heads of Alexander the Great, and naturally claimed for the composite the combined authority of all the artists. In this way Science has recently come into pussession of a new Shakespeare. In the case of Shakespeare the diversity amongst the several originals is strikingly evident, and thus a composite was needed to give a characteristic, individual, natural face. This suggested to $\mathrm{Mr}$. W. C. Taylor the application of the same process to Washington's portraits. He has grouped the several portraits into three groups, owing to the differences of position of the portraits, and the accuracy of the work is well shown by the fact that the agreement amongst the resulting three composites is very close, while the originals show every shade of individual differences. These portraits were first published in the Fournal of the Franklin Institute, and are given on a new and enlarged plate in the number of Science for December II.

IN pursuance of a resolntion passed at the Medical Congress on Brain Diseases, held during the past summer at Antwerp, by which it was suggested that local conferences should be held to draw up trustworthy international tables of statistics on insanity, a Conference of Austro-Hungarian specialists will be held at Vienna on the 26 th and 27 th inst., with the object of revising and extending the nomenclature of mental disorders. Invitations to the Conference have been issued by four leading doctors of Vienna.

THE work of spawning Salmonidæ at the establishment of the National Fish-Culture Association at Delaford Park has com. menced, and it is expected that a large number of ova will be obtained. The establishment, which was opened in the early part of the present year, is now in excellent order, and all the fish that have been reared are doing well. It has been found necessary to increase the number of breeding-ponds in view of the extensive nature of the operations to be carried on next year.

THE new aquarium for the Indian and Colonial fish at South Kensington is now in course of construction and will be on view 